\title{
Congestion in Computational Evacuation Modelling
}

\author{
Volker Schneider ${ }^{1}$, Rainer Könnecke ${ }^{2}$ \\ ${ }_{1,2}$ IST GmbH \\ Feuerbachstraße 19, 60325 Frankfurt, Germany \\ v.schneider@ist-net.de; r.koennecke@ist-net.de
}

\begin{abstract}
The time-based analysis of egress scenarios is a long-standing and well-established method to evaluate occupant safety. It is based on the necessary condition that the required egress time is smaller than the available egress time. The former is derived by the application of evacuation models, the latter by calculation of smoke and heat spread in the case of a fire incident. In the calculation of required egress time the time-dependent development of occupant density and consequently the emergence of congestion often play a crucial role. There is a demand to evaluate the development of local occupant density and jam situations independent of the above time-based criterion. This is for example reflected in national guidelines and standards. It is however difficult to obtain general valid evaluation criteria for congestion due to the multitude of influencing parameter and the highly situation-dependent nature of the accompanying boundary conditions. In addition, prediction of localization and duration of congestion may differ from model to model if applied to equal scenarios. Furthermore, close inspection reveals the difficulty to define proper terms for a quantitative definition of congestion. This issue is further analysed in this paper based on three case studies.
\end{abstract}

Keywords: evacuation, modelling, congestion, egress movement, numerical simulation

\section{Introduction}

For buildings and areas of special size or complexity in combination with a large number of occupants, computational evacuation modelling is often applied to support approval procedures or design processes. Criteria for the time-based analysis of the egress process can be straightforward derived based on the concept of required egress time versus available egress time. More difficult is the assessment of situations involving congestion [1]. This issue is for example addressed in the German Guideline Fire Protection Engineering [2] and in the current work on E DIN 18009-2 that is scheduled to be published next year [3], [4]. Guideline and norm will provide technical definitions and evaluation criteria to assist fire engineers, designers and authorities. The three case studies summarized in this paper will contribute to the characterisation and evaluation of congestion by presenting numerical simulations and respective empirical data.

\section{Benchmark cases for congestion analysis}

The first example consists of a series of plain benchmark cases. For these, a comparison of microscopic simulations using the ASERI evacuation model [5] and macroscopic calculations is performed. By variation of initial and boundary conditions with respect to geometry and population, relevant parameter for the formation and evaluation of congestion e.g. at exits or in front of stairs are developed. This leads to suggestions for the definition and classification of jam situations, including definitions for stand-still times and methods for analysing local occupant density. A statistical analysis is performed, as described exemplary in figure 1. This graphical representation describes the number of people in a jam in front of a descending stair that are affected by a certain reduction of unrestricted walking speed or stand-still for at least a certain time interval. 


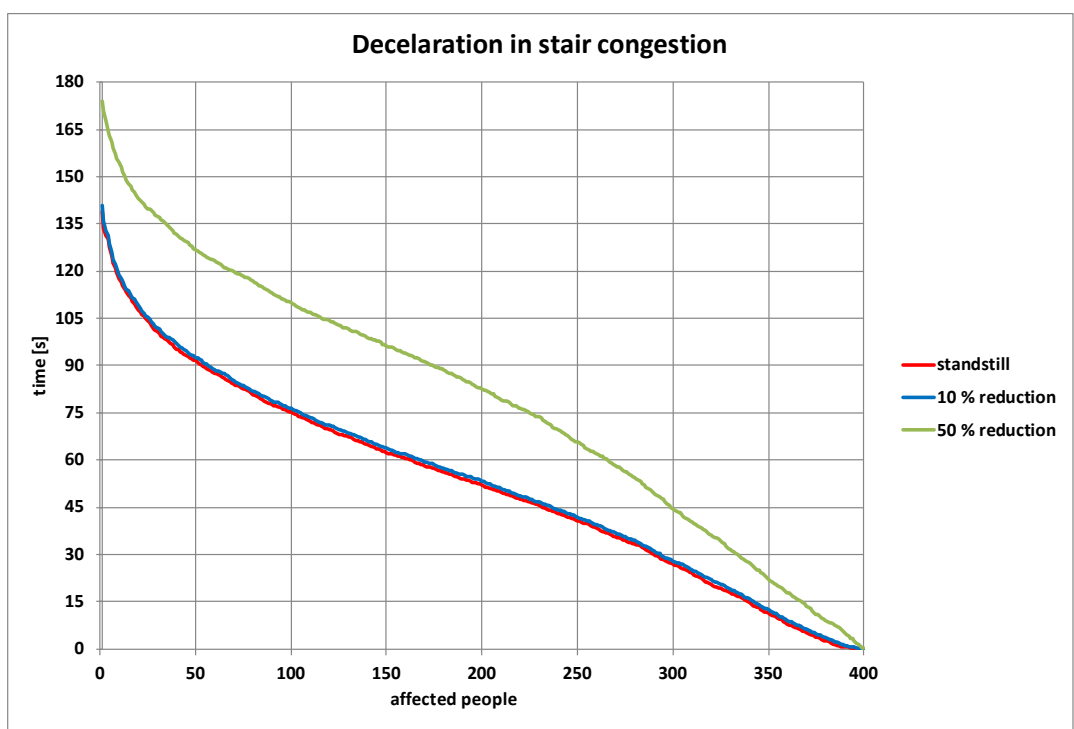

Fig. 1: Distribution of reduced walking speed in congestion scenarios

\section{Evacuation of an Auditorium}

The second case is the evacuation of an auditorium - a scenario documented in the guideline [2] that is presently updated for the next revised edition scheduled for 2019. Numerical studies applying several evacuation models show some differences that include also the localization of congestion along the available egress paths. Table 1 shows the escape times and localizations of congestion as derived by the various models.

Table 1: Calculated escape times and congestion characteristics [2]

\begin{tabular}{|l|c|l|c|c|}
\hline \multicolumn{1}{|c|}{ Model } & \multicolumn{2}{|c|}{ first escape route } & \multicolumn{2}{c|}{ second escape route } \\
\hline $\begin{array}{l}\text { Capacity analysis } \\
\text { (SFPE) }\end{array}$ & $304 \mathrm{~s}$ & Entrance door & $298 \mathrm{~s}$ & Emergency exit \\
\hline $\begin{array}{l}\text { Predtetschenski \& } \\
\text { Milinski }\end{array}$ & $295 \mathrm{~s}$ & $\begin{array}{l}\text { Aisle stairways } \\
\text { Foyer stairs }\end{array}$ & $318 \mathrm{~s}$ & Aisle stairways \\
\hline buildingEXODUS & $382 \mathrm{~s}$ & Aisle stairways & $266 \mathrm{~s}$ & Aisle stairways \\
\hline PedGo & $348 \mathrm{~s}$ & $\begin{array}{l}\text { Aisle stairways } \\
\text { Foyer stairs } \\
\text { Main exits }\end{array}$ & $276 \mathrm{~s}$ & $\begin{array}{l}\text { Aisle stairways } \\
\text { Emergency exit }\end{array}$ \\
\hline FDS+Evac & $373 \mathrm{~s}$ & $\begin{array}{l}\text { Aisle stairways } \\
\text { Main exits }\end{array}$ & $239 \mathrm{~s}$ & Aisle stairways \\
\hline ASERI & $324 \mathrm{~s}$ & $\begin{array}{l}\text { Aisle stairways } \\
\text { Main exits }\end{array}$ & $311 \mathrm{~s}$ & $\begin{array}{l}\text { Aisle stairways } \\
\text { Emergency exit }\end{array}$ \\
\hline
\end{tabular}

\section{Empirical flow data for a large ice hockey arena}

The last case covers a monitored ingress and egress situation inside a large ice hockey arena. Starting at first admittance and ending after the last spectators had left the arena, the inflow, outflow and the distribution on the spectators on a grandstand where monitored by cameras above the playing field and counted by supporters. The snapshot in figure 2 taken from one of these videos illustrates the situation shortly after the final whistle. Two examples of the evaluation of the counting are added (figure 3 ). The first one shows the dwell time (yellow curve) for the grand stand and the temporary outflow (blue curve) with peaks at the breaks of the game. The second graph presents total inflow and outflow. This data will be used for a more detailed analysis of the formation and decomposition of jams. 


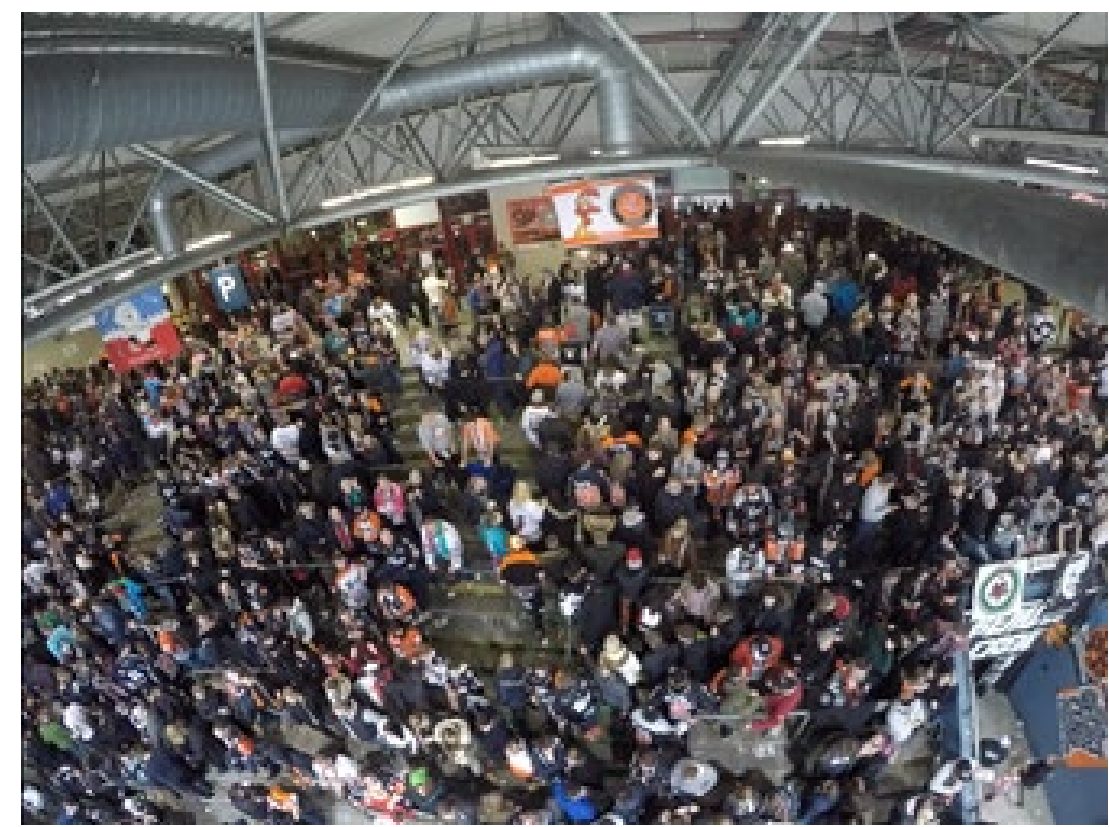

Fig. 2: Egress from an ice hockey arena - C IST GmbH
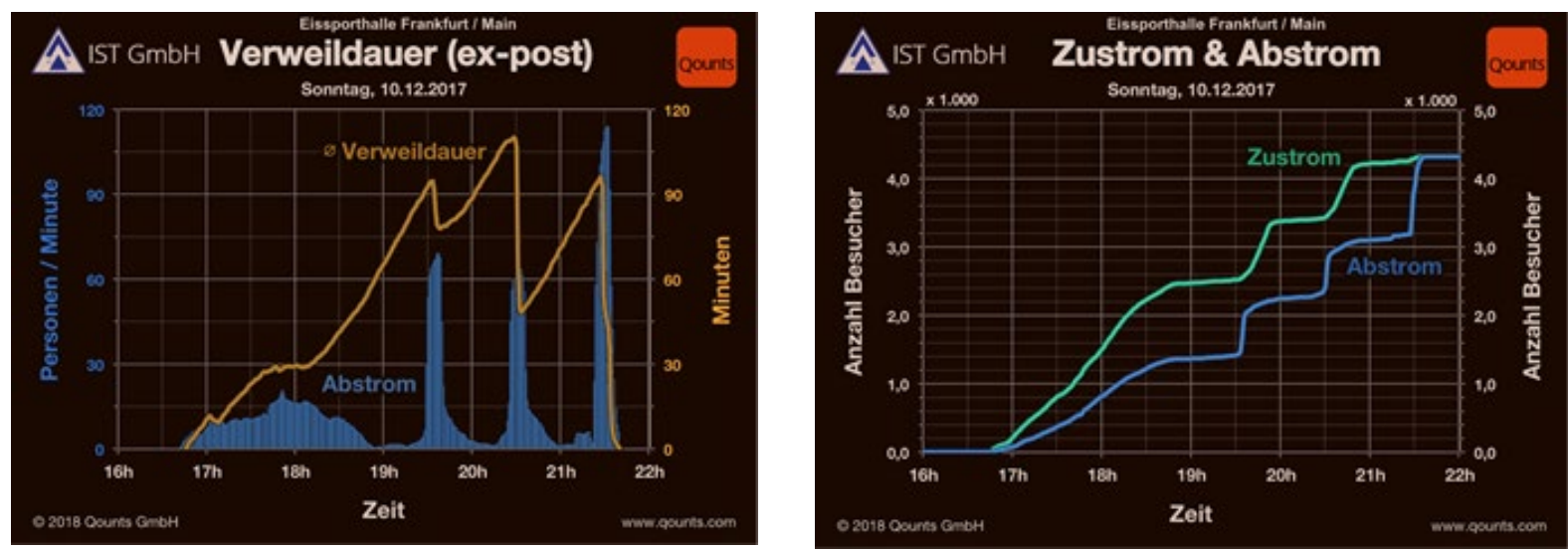

Fig. 3: Dwell time (Verweildauer), inflow (Zustrom) and outflow (Abstrom) for the grand stand during an ice hockey match - (C) Qounts GmbH

\section{Acknowledgements}

The authors wish to thank Stefan Leitmannslehner (Qounts GmbH, Göttingen) for the data monitoring and analysis presented in section 4 .

\section{References}

[1] V. Schneider, "Räumungssimulationen - Genügen Räumungszeiten für eine Bewertung der Personensicherheit?" in Proceedings of the vfdb Jahresfachtagung 2016, Stuttgart, Mai 2016.

[2] D. Hosser (Ed.), "Guideline Fire Protection Engineering" vfdb Technical Report TR 04-01, November 2013.

[3] A. Seyfried, G. Jäger, M. Kitzlinger, B. Schröder, "Normierung von Personenstromsimulationen in DIN 18009-2" in Proceedings of the Braunschweiger Brandschutztage 2015, September 2015.

[4] J. Wiese, "Personenstromsimulationen nach E DIN 18009-2" in Proceedings of the vfdb Jahresfachtagung 2018, Duisburg, Mai 2018.

[5] V. Schneider, "Application of the individual-based evacuation model ASERI in designing safety concepts" in Proceedings of the 2nd Int. Symp. on Human Behaviour in Fire, Boston, March 2001. 